\title{
In Vivo Dopamine Transporter Imaging in a Unilateral 6-Hydroxydopamine Rat Model of Parkinson Disease Using ${ }^{11}$ C-Methylphenidate PET
}

\author{
Vesna Sossi ${ }^{1,2}$, Katherine Dinelle ${ }^{1,2}$, Salma Jivann ${ }^{2,3}$, Kristina Fischer ${ }^{4}$, James E. Holden ${ }^{5}$, and Doris Doudet ${ }^{2,6}$ \\ ${ }^{I}$ Department of Physics and Astronomy, University of British Columbia, Vancouver, British Columbia, Canada; ${ }^{2}$ PET Imaging Group, \\ University of British Columbia, Vancouver, British Columbia, Canada; ${ }^{3}$ Triumf, Vancouver, British Columbia, Canada; ${ }^{4}$ Department \\ of Preclinical Imaging and Radiopharmacy, University of Tuebingen, Tuebingen, Germany; ${ }^{5}$ Department of Medical Physics, \\ University of Wisconsin, Madison, Wisconsin; and ${ }^{6}$ Department of Medicine, University of British Columbia, Vancouver, British \\ Columbia, Canada
}

Dopamine transporter (DAT) function is altered by many neurodegenerative diseases. For instance, in Parkinson disease DAT density has been shown to decrease in early disease and to play a role in the occurrence of motor complications. DAT is thus an important imaging target with potential therapeutic relevance in humans and animal models of disease. The PET DAT marker ${ }^{11} \mathrm{C}-$ methylphenidate is commonly used to quantify DAT function. Here we investigate the characteristics of the ${ }^{11} \mathrm{C}$-methylphenidate-derived quantification of DAT in rodents using the 6-hydroxydopamine Parkinson disease rat model. Methods: Seven unilaterally 6-hydroxydopamine-lesioned rats (dopaminergic denervation [DD] range, $36 \%-94 \%$ ) were injected with $3.7 \mathrm{MBq} / 100 \mathrm{~g}$ of body weight and tracer masses ranging from 93.8 to $0.0041 \mu \mathrm{g} / 100 \mathrm{~g}$ of body weight. We evaluated the maximum available transporter density and the in vivo (apparent) ligand-transporter dissociation constant $\left(B_{\max }\right.$ and $\mathrm{K}_{\mathrm{d}}^{\mathrm{app}}$, respectively) with an in vivo Scatchard method using several modeling approaches and estimated the transporter occupancy as a function of the amount of tracer injected and tracer specific activity (SA). Results: Strong evidence of different nonspecific binding in the striatal region, compared with the reference region, leading to bias in the estimate of DD severity was found. One percent transporter occupancy was reached with $0.14 \mu \mathrm{g}$ of tracer $/ 100 \mathrm{~g}$ of body weight, corresponding to an SA of $5.7 \mathrm{kBq} / \mathrm{pmol}$ for the given radioactivity dose, and $10 \%$ occupancy was reached at $1.5 \mu \mathrm{g}$ of tracer/100 g of body weight, corresponding to an SA of $0.57 \mathrm{kBq} /$ pmol. The 6-hydroxydopamine lesion affected $\mathrm{B}_{\max }$ (control, $402 \pm$ $94 \mathrm{pmol} / \mathrm{mL}$; lesioned, $117 \pm 120 \mathrm{pmol} / \mathrm{mL} ; P=0.003$ ) but not $\mathrm{K}_{\mathrm{d}}^{\text {app }}$ (control, $331 \pm 63 \mathrm{pmol} / \mathrm{mL}$; lesioned, $362 \pm 119 \mathrm{pmol} / \mathrm{mL} ; P=$ 0.63). Conclusion: Although DAT imaging can be performed at a relatively high mass of ${ }^{11} \mathrm{C}$-methylphenidate (low SA), the additional nonspecific binding found in the striatum can introduce a DD severity-dependent bias in the estimate of tissue-derived binding potential and care must be taken in comparing ${ }^{11} \mathrm{C}$ methylphenidate-derived assessment of DD with that obtained using other dopaminergic tracers.

Received Nov. 30, 2011; revision accepted Feb. 14, 2012.

For correspondence or reprints contact: Vesna Sossi, Department of Physics and Astronomy, 6224 Agricultural Rd., Vancouver, B.C. V6T 1 Z1 Canada.

E-mail: vesna@physics.ubc.ca

Published online Apr. 9, 2012

COPYRIGHT @ 2012 by the Society of Nuclear Medicine, Inc.
Key Words: PET; DAT imaging; rodent; Parkinson's model

J Nucl Med 2012; 53:813-822

DOI: 10.2967/jnumed.111.101436

$\mathbf{T}$ oxin-induced and transgenic rodent models of human disease are becoming increasingly more relevant to the investigation of specific disease mechanisms and pathogenesis and the evaluation of potential effects of novel treatment strategies. Although potentially quite informative, animal models must be validated against human disease. Noninvasive molecular imaging, such as PET, can aid by providing common investigative protocols in which biologically relevant outcomes can be directly compared. To ensure a meaningful comparison, rodent brain imaging must be accurately characterized to avoid potential methodologic confounding effects due to the smaller size of the rodent brain and potential differences in tracer metabolism and binding. Although dedicated small-animal scanners, capable of approximately $(1.5 \mathrm{~mm})^{3}$ resolution, partially address the imaging resolution limitations, a stricter limit on the amount of administered tracer must be used to avoid pharmacologic effects. Given that the injected tracer radioactivity dose needs to be maintained sufficiently high to obtain statistically meaningful data, the tracer must be produced at a specific activity (SA) high enough to ensure negligible tracer mass effect. This limit, together with potential differences in tracer binding and metabolism, are tracerand species-dependent and must be characterized for each case separately.

Multitracer PET of the dopaminergic system has been performed for decades on human subjects with Parkinson disease, a debilitating condition of still unknown etiology, affecting approximately $300 / 100,000$ of the general population (1) and characterized by dopaminergic neuronal degeneration. There is ample evidence that the membrane dopamine transporter (DAT) is affected by disease. The nature of the implication of DAT in Parkinson disease is controversial: it could contribute to the origin of the disease 
(2-5), or it could delay the onset of clinical symptoms by compensatory downregulation (6). It might also be functionally associated with an increased risk of occurrence of treatmentrelated motor and psychiatric complications (7-9). DAT has also been used as a surrogate marker of treatment efficacy, with inconsistent outcomes (10-12). These unresolved questions render DAT an important target of investigation. A radiotracer commonly used to evaluate DAT binding availability in humans is ${ }^{11} \mathrm{C}$-methylphenidate. We thus undertook a characterization of DAT imaging with ${ }^{11} \mathrm{C}$-methylphenidate in the commonly used 6-hydroxydopamine rat model of Parkinson disease $(10,13,14)$. We estimated the typical maximum available transporter density and in vivo (apparent) ligand-transporter dissociation constant $\left(\mathrm{B}_{\max }\right.$ and $\mathrm{K}_{\mathrm{d}}^{\text {app }}$, respectively) and their dependence on the severity of dopaminergic denervation (DD). We also evaluated the consistency between different modeling approaches to the determination of $\mathrm{B}_{\max }$ and $\mathrm{K}_{\mathrm{d}}^{\text {app }}$ and explored the validity of the assumption that the amount of nonspecific binding is consistent between the target and reference region, a requisite condition to obtain unbiased estimates of the tissue input-derived nondisplaceable binding potential $\left(\mathrm{BP}_{\mathrm{ND}}=\mathrm{B}_{\max } / \mathrm{K}_{\mathrm{d}} \times \mathrm{f}_{2}\right.$, where $\mathrm{f}_{2}$ is the fraction of tracer that is freely dissolved in tissue) (15). Finally, useful limits on the tracer SA or amount necessary to ensure lack of tracer pharmacologic effects were determined by investigating transporter occupancy as a function of amount of tracer administered and SA.

\section{MATERIALS AND METHODS}

\section{Group-Derived $B_{\max }$ and $K_{d}^{\text {app }}$}

Data from the control striatum from all animals (here denoted as group) were used to determine the group-derived $\mathrm{B}_{\max }$ and $\mathrm{K}_{\mathrm{d}}^{\mathrm{app}}$ according to Equations 1 and 2.

$$
\begin{gathered}
\left(\frac{\mathrm{B}}{\mathrm{F}}\right)_{e}=\frac{\mathrm{B}_{\max }}{\mathrm{K}_{\mathrm{D}}^{\mathrm{app}}+\mathrm{F}} \\
\left(\frac{\mathrm{B}}{\mathrm{F}}\right)_{e}=\frac{\mathrm{B}_{\max }}{\mathrm{K}_{\mathrm{D}}^{\text {app }}+\mathrm{F}}+\mathrm{NS}
\end{gathered}
$$

where $\mathrm{F}(\mathrm{pmol} / \mathrm{mL})$ is the free and nonspecifically bound tracer concentration in tissue, estimated from the cerebellar radioactivity concentration $\mathrm{C}$ averaged over the last $30 \mathrm{~min}$ of the scan (3060 min after tracer injection) and the tracer SA as C/SA, and (B/ $\mathrm{F})_{\mathrm{e}}$ is the estimated reference tissue input binding potential at different concentrations of F, obtained by varying SA. $(\mathrm{B} / \mathrm{F})_{\mathrm{e}}$ was evaluated using the Logan graphical approach (16) and the simplified reference tissue method (SRTM) (17). For the Logan approach, the term containing the reference tissue clearance rate constant $k_{2}{ }^{\prime}$ was neglected (18) and the Logan slope was calculated from 30 to $60 \mathrm{~min}$ after tracer injection. The use of the cerebellar tracer concentration to obtain an estimate of $\mathrm{F}$ is based on the assumption that the concentration of free and nonspecifically bound tracer in the target (the striatum) and reference region (the cerebellum) is the same. A violation of this assumption would manifest itself through the need to introduce an extra term to account for the difference; such a term (NS) is introduced in Equation 2 (19). The group analysis is also based on the assumption that the variability of $B_{\max }$ and
$\mathrm{K}_{\mathrm{d}}^{\mathrm{app}}$ between animals is negligible compared with the tracer mass effect: this analysis was thus applied only to the data obtained from the control striatum of each rat. Potential lesion-induced compensatory changes on the control side would be minimal and were considered irrelevant for the purpose of this study.

\section{Determination of $B_{\max }$ and $K_{d}^{\text {app }}$ Using the Multiple Ligand Concentration Transporter Assay (MLCTA): Individual Animals}

The MLCTA (20) is based on the relation between the equilibrium concentration of the bound ligand (B) and the free and nonspecifically bound ligand (F). In addition to Equation 1, two other relationships were used to estimate the relevant parameters from the data of each animal and each striatum separately:

$$
\begin{gathered}
\left(\frac{\mathrm{B}}{\mathrm{F}}\right)_{\mathrm{e}}=\mathrm{BP}_{\mathrm{ND}}-\frac{\mathrm{B}}{\mathrm{K}_{\mathrm{D}}^{\text {app }}} \\
\left(\frac{\mathrm{B}}{\mathrm{F}}\right)_{\mathrm{e}}=\mathrm{BP}_{\mathrm{ND}}-\frac{\left(\frac{\mathrm{B}}{\mathrm{F}}\right)_{\mathrm{e}} \cdot \mathrm{F}}{\mathrm{K}_{\mathrm{D}}^{\mathrm{app}}} .
\end{gathered}
$$

Here $\mathrm{BP}_{\mathrm{ND}}$ represents the tissue input-derived binding potential extrapolated to zero transporter occupancy and $\mathrm{B}(\mathrm{pmol} / \mathrm{mL})$ is the bound tracer calculated as $(\mathrm{S}-\mathrm{C}) / \mathrm{SA}$, where $\mathrm{S}$ and $\mathrm{C}$ are cerebellar and striatal radioactivity concentrations averaged from 30 to $60 \mathrm{~min}$ of the scan. Equations 3 and 4 are equivalent if the tracer has reached equilibration during the scan and if $F$ is the same in the target and reference region. Equation 4 differs from Equation 1 only to the extent that it requires a linear instead of a nonlinear fitting method. In light of the results obtained when estimating the group-derived $B_{\max }$ and $K_{d}^{\text {app }}$ (see "Results"), the nonlinear fit described by Equation 2 was applied to each individual striatum with the NS value constrained to the value obtained from the group data. In addition, an equivalent linear expression was fitted to the data of each individual striatum:

$$
\left(\frac{\mathrm{B}}{\mathrm{F}}\right)_{\mathrm{e}}-\mathrm{NS}=\mathrm{BP}_{\mathrm{ND}}-\frac{\left(\left(\frac{\mathrm{B}}{\mathrm{F}}\right)_{\mathrm{e}}-\mathrm{NS}\right) \cdot F}{\mathrm{~K}_{\mathrm{D}}^{\mathrm{app}}}
$$

Again, here NS is the parameter estimated from the group analysis using Equation 2. Two parameters were obtained from each fit (either $\mathrm{BP}_{\mathrm{ND}}$ and $\mathrm{K}_{\mathrm{d}}^{\mathrm{app}}$ or $\mathrm{B}_{\max }$ and $\mathrm{K}_{\mathrm{d}}^{\mathrm{app}}$ ), and the fitting was performed on data obtained either from 3 scans (high to medium-low SA [3-point Scatchard]), 4 scans (high to low SA [4-point Scatchard]), or 5 scans (2 animals only) (Table 1).

\section{DD Severity Estimate}

Denervation severity (DD) was estimated from the measured $(\mathrm{B} / \mathrm{F})_{\mathrm{e}}$ values as

$$
\mathrm{DD}=1-\left((\mathrm{B} / \mathrm{F})_{\mathrm{e}}\right)_{\text {lesion side }} /\left((\mathrm{B} / \mathrm{F})_{\mathrm{e}}\right)_{\text {control side }} \quad \text { Eq. } 6
$$

and

$$
\mathrm{DD}_{-\mathrm{NS}}=1-\left((\mathrm{B} / \mathrm{F})_{\mathrm{e}}-\mathrm{NS}\right)_{\text {lesion side }} /\left((\mathrm{B} / \mathrm{F})_{\mathrm{e}}-\mathrm{NS}\right)_{\text {control side. }}
$$

The least biased estimate of DD was deemed to be that obtained with $(\mathrm{B} / \mathrm{F})_{\mathrm{e}}$ estimated from the high-SA scans, since it 
TABLE 1

SA Limits* and Tracer Amount Range Used for Imaging

\begin{tabular}{lcc}
\hline & SA $(\mathrm{kBq} / \mathrm{pmol})$ & $\begin{array}{c}\text { Tracer amount } \\
(\mu \mathrm{g} / 100 \mathrm{~g} \text { of } \\
\text { body weight })\end{array}$ \\
\hline Very low (2 rats only) & $<0.011$ & $>80$ \\
Low & $0.0185-0.045$ & $20-39$ \\
Medium-Low & $0.1-0.655$ & $1.5-11$ \\
Medium-High & $0.34-6.1$ & $0.14-2.5$ \\
High & $>64.75$ & $<0.014$
\end{tabular}

*Valid for injected dose of $3.7 \mathrm{MBq} / 100 \mathrm{~g}$ of body weight).

best approximates the true $\mathrm{BP}_{\mathrm{ND}}$. An estimate of $\mathrm{DD}$ was also obtained as:

$$
\mathrm{DD}=1-\left(\mathrm{B}_{\max }\right)_{\text {lesioned side }} /\left(\mathrm{B}_{\max }\right)_{\text {control side }} .
$$

If indeed 6-hydroxydopamine lesioning results in a change in $\mathrm{B}_{\max }$ and not $\mathrm{K}_{\mathrm{d}}^{\mathrm{app}}$, DD estimated from $(\mathrm{B} / \mathrm{F})_{\mathrm{e}}$ and $\mathrm{B}_{\max }$ should agree, assuming that reliable estimates of $B_{\max }$ can be obtained.

\section{Occupancy}

Transporter occupancy was defined as Occ $=1-(\mathrm{B} / \mathrm{F})_{\mathrm{e}} \mathrm{sA} /$ $(\mathrm{B} / \mathrm{F})_{\mathrm{e}}$ highSA $(15)$ and as $\mathrm{Occ}_{-\mathrm{NS}}=1-\left((\mathrm{B} / \mathrm{F})_{\mathrm{e} \mathrm{SA}}-\mathrm{NS}\right) /(1-$ $(\mathrm{B} / \mathrm{F})_{\mathrm{e}}$ highSA $\left.-\mathrm{NS}\right)$, was plotted as a function of $\log _{10}(1 / \mathrm{SA})$, and was fitted to the expression Occ $=1 /\left(1+\mathrm{K}_{\mathrm{d}}^{\mathrm{app}^{\prime}} \times \mathrm{SA}\right)$, where $\mathrm{K}_{\mathrm{d}}^{\mathrm{app}}$ is the apparent dissociation constant expressed in units of 1/SA (pmol/kBq). Considering that each rat was injected with approximately $3.7 \mathrm{MBq} / 100 \mathrm{~g}, 1 / \mathrm{SA}$ is a measure of the total mass of tracer injected per unit body weight. To visualize the latter relation, Occ was also plotted as a function of the injected tracer amount $(\mu \mathrm{g})$ normalized to $100 \mathrm{~g}$ of animal weight (amount $=$ mass of injected tracer amount $(\mu \mathrm{g})$ per $100 \mathrm{~g}$ of animal weight) and fitted to the expression Occ $=1 /\left(1+\mathrm{K}_{\mathrm{d}}^{\mathrm{app}}\right.$ "/amount $)$, where $\mathrm{K}_{\mathrm{d}}^{\mathrm{app}}$ is the apparent dissociation constant expressed in units of micrograms of injected tracer/100 $\mathrm{g}$ of animal weight. The occupancy curves were determined only for the control side of the striatum, since in the lesioned animals occupancy values were found to be in some cases too noisy, thus leading to unrealistic occupancy values (see "Results").

\section{Chemistry, Stock Solution Preparation, and SA Adjustment and Measurement}

${ }^{11} \mathrm{C}$-methylphenidate was synthesized using a published method (21) and provided greater than $95 \%$ radiochemically pure $d$-threo- ${ }^{11} \mathrm{C}$ methylphenidate with SA of greater than $55.5 \mathrm{kBq} / \mathrm{pmol}$ at the end of synthesis. A known amount of ${ }^{11} \mathrm{C}$-methylphenidate, ranging from 12.5 to $125 \mu \mathrm{g}$, was added to the high-SA ${ }^{11} \mathrm{C}$-methylphenidate sample using the stock solution (supplemental material, available online at http://jnm.snmjournals.org).

\section{Animals}

Seven male Sprague-Dawley rats $(604 \pm 39 \mathrm{~g}$ at the time of scanning) unilaterally lesioned with 6-hydroxydopamine were included in the study. Lesioning was performed as previously described (22). Briefly, the animals were anesthetized with isoflurane and placed in the stereotactic headholder with the skull flat between lambda and bregma. A $2 \%$ solution of 6-hydroxydopamine hydrobromide was infused at 2 sites ( 2 animals) along the medial forebrain bundle. Five animals had only 1 infusion of the 6-hydroxydopamine solution at 1 site so as to achieve a varying degree of denervation. Approximately $30 \mathrm{~min}$ before the 6-hydroxydopamine infusion, the animals were given desipramine $(25 \mathrm{mg} / \mathrm{kg}$ intraperitoneally) to protect noradrenergic fibers (23). The animals were allowed at least 3-4 wk recovery before undergoing the PET studies.

\section{Scanning}

The rats were anesthetized and maintained with a $2 \%$ isoflorane $/ \mathrm{O}_{2}$ gas mixture. All studies were performed on a Siemens/ Concorde microPET Focus 120 (24). Each rat was positioned in a stereotactic headholder mounted to the scanner bed, allowing accurate repositioning of the animal within the ear bars and the mouthpiece. After a 6-min transmission scan with a ${ }^{57}$ Co source, a 61-min-long dynamically acquired emission scan was performed starting at injection (supplemental material). A 3.7-MBq bolus of tracer per $100 \mathrm{~g}$ of body weight was administered, with SA ranging from 0.009 to $191 \mathrm{kBq} / \mathrm{pmol}$, corresponding to a tracer mass ranging from 93.8 to $0.0041 \mu \mathrm{g} / 100 \mathrm{~g}$ of body weight as detailed in Table 1.

To limit the amount of time the rats were kept under anesthesia, each rat underwent at most 2 scans per day, for which the 2 tracer injections were administered $120 \mathrm{~min}$ apart. The higher-SA scan was always performed first to minimize potential residual tracer occupancy effects. All procedures were approved by the University of British Columbia Animal Care Committee.

\section{Data Analysis}

The high-SA tracer scan was used as a reference image for analysis of the medium- and low-SA scans. First, a brain atlas (25) was manually coregistered to the brain area in the high-SA scans summed over data from the entire dynamic sequence (supplemental material). Using the coregistered atlas for guidance, we placed a rectangular $(2.6 \times 3.5) \mathrm{mm}^{2}$ region of interest on each striatum on 3 consecutive transaxial planes (plane thickness, $0.796 \mathrm{~mm}$ ) and a $(6.9 \times 2.6) \mathrm{mm}^{2}$ region of interest on the cerebellum. The regions of interest were then replicated on each frame of the dynamic sequence for the extraction of a time-activity curve. Each medium- and low-SA scan was coregistered to the high-SA scan. The regions of interest defined on the high-SA scan were carried over to the coregistered medium- and low-SA scans for timeactivity curve extraction.

\section{RESULTS}

\section{Comparison of $(B / F)_{e}$ Obtained with the Logan and SRTM Methods}

Excellent correlation between $(\mathrm{B} / \mathrm{F})_{\mathrm{e}}$ obtained with the Logan and the SRTM methods was observed throughout the range of estimated $(\mathrm{B} / \mathrm{F})_{\mathrm{e}}(0.08-1.45)$ with $(\mathrm{B} / \mathrm{F})_{\mathrm{e}}(\mathrm{SRTM})=$ $0.984,(\mathrm{~B} / \mathrm{F})_{\mathrm{e}}(\log a n)-0.0008$ and $r^{2}=0.996$. The mean $(\mathrm{B} / \mathrm{F})_{\mathrm{e}}$ value across animals at high $\mathrm{SA}$ was $1.32 \pm 0.16$ $($ mean \pm SD) with the SRTM method and $1.35 \pm 0.17$ (mean $\pm \mathrm{SD}$ ) with the Logan method. We thus arbitrarily decided to use only the SRTM-derived $(B / F)_{e}$ in all subsequent analyses.

\section{Group-Derived $\mathbf{B}_{\max }$ and $\mathbf{K}_{\mathbf{d}}^{\text {app }}$}

$(B / F)_{e}$ as a function of $F$ for the control striatum and the corresponding nonlinear fits obtained with Equations 1 and 2 are shown in Figure 1. The fit with the expression 


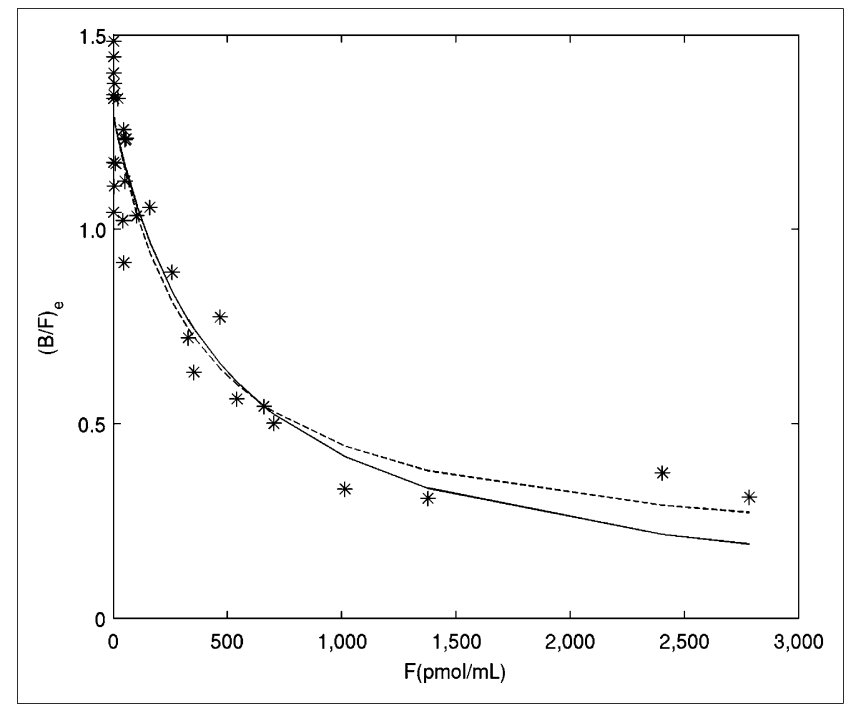

FIGURE 1. (B/F) evaluated with SRTM vs. F derived from radioactivity concentration in cerebellar region fitted according to Equation 1 (solid line) and Equation 2 (dashed line) for control striatum of all animals.

including the NS term (Eq. 2) outperformed that without the NS term (Eq. 1) according to the Akaike information criterion and visually accounted better for the observed trend in the data at high values of $\mathrm{F}$ (low SA). The corresponding NS value was 0.14 . Group-derived $B_{\max }, K_{d}^{\text {app }}$, and $\mathrm{BP}_{\mathrm{ND}}$ were $623 \mathrm{pmol} / \mathrm{mL}, 485 \mathrm{pmol} / \mathrm{mL}$, and 1.28 , respectively, without inclusion of the NS term in the fit, and 412 $\mathrm{pmol} / \mathrm{mL}, 357 \mathrm{pmol} / \mathrm{mL}$, and 1.15 , respectively, with the NS term subtracted.

\section{Determination of $B_{\max }$ and $K_{d}^{\text {app }}$ Using MLCTA: Control Side}

Individual $\mathrm{B}_{\max }$ and $\mathrm{K}_{\mathrm{d}}^{\mathrm{app}}$ values estimated from the 3-, 4-, and 5-point Scatchard plots (the latter only for rats 6 and 7) are listed in Table 2, and example fits obtained with Equations 4 and 5 are shown in Figure 2. The 2 different estimates of the bound tracer concentration (Eqs. 3 and 4) lead to greatly different $B_{\max }$ and $K_{d}^{\text {app }}$, and the 4-point Scatchard fits lead to higher values of $B_{\max }$ and $K_{d}^{\text {app }}$, compared with the 3-point Scatchard (and even higher when 5 points are considered for rats 6 and 7) when the NS term is not subtracted. The linear fit and the nonlinear fits yield consistent values, and subtraction of the NS term decreases the dependence of the $\mathrm{B}_{\max }$ and $\mathrm{K}_{\mathrm{d}}^{\mathrm{app}}$ values on the number of points and thus range of $F$ included in the fit. A comparison of the coefficient of variation (Table 2) indicates that more consistent results are obtained when 4 points are included in the fit than when 3 are included. Interestingly, whereas inclusion of the NS term minimizes the dependence of the $\mathrm{B}_{\max }$ and $\mathrm{K}_{\mathrm{d}}^{\text {app }}$ estimates on the range of $\mathrm{F}$ on average, it also increases the coefficient of variation. This is likely due to the fact that a common value of NS was used for all rats. NS could not be determined for each individual animal separately since the range of $F$ values spanned for each animal was not sufficiently large. The averages of the $B_{\max }$ and $K_{d}^{\text {app }}$ values

TABLE 2

$\mathrm{B}_{\max }$ and $\mathrm{K}_{\mathrm{d}}^{\mathrm{app}}$ for Individual Rats (R1-R7): Control Side

\begin{tabular}{|c|c|c|c|c|c|c|c|c|c|c|c|c|}
\hline Fit & Variables & Points & NS & $\mathrm{R} 1$ & $\mathrm{R} 2$ & R3 & $\mathrm{R} 4$ & $\mathrm{R} 5$ & $\mathrm{R} 6$ & $\mathrm{R} 7$ & Mean & COV (\%) \\
\hline \multicolumn{13}{|l|}{$\mathrm{B}_{\max }$} \\
\hline \multirow[t]{6}{*}{ Linear } & $B=S-C($ Eq. 3) & 3 & $\mathrm{~N}$ & 977 & 752 & 884 & 608 & 409 & 600 & 647 & 697 & 27 \\
\hline & $B=S-C($ Eq. 3) & 4 & $\mathrm{~N}$ & 937 & 789 & 1086 & 700 & 875 & 1085 & 876 & 907 & 16 \\
\hline & $\mathrm{B}=(\mathrm{B} / \mathrm{F})_{\mathrm{e}} \times \mathrm{F}(\mathrm{Eq} .4)$ & 3 & $\mathrm{~N}$ & 681 & 502 & 620 & 388 & 268 & 376 & 460 & 471 & 31 \\
\hline & $\mathrm{B}=(\mathrm{B} / \mathrm{F})_{\mathrm{e}} \times \mathrm{F}(\mathrm{Eq} .5)$ & 3 & $\mathrm{Y}$ & 513 & 362 & 484 & 301 & 200 & 284 & 367 & 359 & 31 \\
\hline & $\mathrm{B}=(\mathrm{B} / \mathrm{F})_{\mathrm{e}} \times \mathrm{F}$ (Eq. 4) & 4 & $\mathrm{~N}$ & 617 & 512 & 763 & 552 & 527 & 474 & 541 & 569 & 17 \\
\hline & $\mathrm{B}=(\mathrm{B} / \mathrm{F})_{\mathrm{e}} \times \mathrm{F}(\mathrm{Eq} .5)$ & 4 & $\mathrm{Y}$ & 426 & 352 & 563 & 354 & 355 & 239 & 267 & 365 & 29 \\
\hline \multirow[t]{4}{*}{ Nonlinear } & $\mathrm{F}$ (Eq. 1) & 4 & $\mathrm{~N}$ & 640 & 517 & 725 & 487 & 504 & 462 & 521 & 551 & 17 \\
\hline & $F(E q .2)$ & 4 & $\mathrm{Y}$ & 458 & 364 & 537 & 320 & 335 & 250 & 309 & 368 & 27 \\
\hline & $F(E q .1)$ & 5 & $\mathrm{~N}$ & & & & & & 688 & 668 & & \\
\hline & $F(E q .2)$ & 5 & $\mathrm{Y}$ & & & & & & 334 & 342 & & \\
\hline \multicolumn{13}{|l|}{$\mathrm{K}_{\mathrm{d}}^{\mathrm{app}}$} \\
\hline \multirow[t]{6}{*}{ Linear } & $B=S-C($ Eq. 3) & 3 & $\mathrm{~N}$ & 718 & 542 & 610 & 441 & 366 & 522 & 455 & 522 & 22 \\
\hline & $B=S-C($ Eq. 3) & 4 & $\mathrm{~N}$ & 686 & 572 & 761 & 517 & 811 & 960 & 624 & 704 & 22 \\
\hline & $\mathrm{B}=(\mathrm{B} / \mathrm{F})_{\mathrm{e}} \times \mathrm{F}(\mathrm{Eq} .4)$ & 3 & $\mathrm{~N}$ & 505 & 365 & 429 & 282 & 240 & 327 & 324 & 353 & 25 \\
\hline & $\mathrm{B}=(\mathrm{B} / \mathrm{F})_{\mathrm{e}} \times \mathrm{F}(\mathrm{Eq} .5)$ & 3 & $\mathrm{Y}$ & 424 & 292 & 371 & 243 & 205 & 282 & 286 & 300 & 25 \\
\hline & $\mathrm{B}=(\mathrm{B} / \mathrm{F})_{\mathrm{e}} \times \mathrm{F}$ (Eq. 4) & 4 & $\mathrm{~N}$ & 453 & 373 & 536 & 418 & 487 & 415 & 383 & 438 & 13 \\
\hline & $\mathrm{B}=(\mathrm{B} / \mathrm{F})_{\mathrm{e}} \times \mathrm{F}(\mathrm{Eq} .5)$ & 4 & $\mathrm{Y}$ & 344 & 283 & 437 & 293 & 376 & 235 & 204 & 310 & 26 \\
\hline \multirow[t]{4}{*}{ Nonlinear } & F (Eq. 1) & 4 & $\mathrm{~N}$ & 472 & 377 & 505 & 361 & 463 & 405 & 368 & 422 & 14 \\
\hline & $F(E q .2)$ & 4 & $\mathrm{Y}$ & 376 & 295 & 413 & 260 & 353 & 247 & 239 & 312 & 22 \\
\hline & $F(E q .1)$ & 5 & $\mathrm{~N}$ & & & & & & 611 & 477 & & \\
\hline & $\mathrm{F}$ (Eq. 2) & 5 & $\mathrm{Y}$ & & & & & & 334 & 266 & & \\
\hline
\end{tabular}

$\mathrm{COV}=$ coefficient of variation; $\mathrm{N}=$ no NS subtraction; $\mathrm{Y}=\mathrm{NS}$ subtraction.

Data are $\mathrm{pmol} / \mathrm{mL}$. 


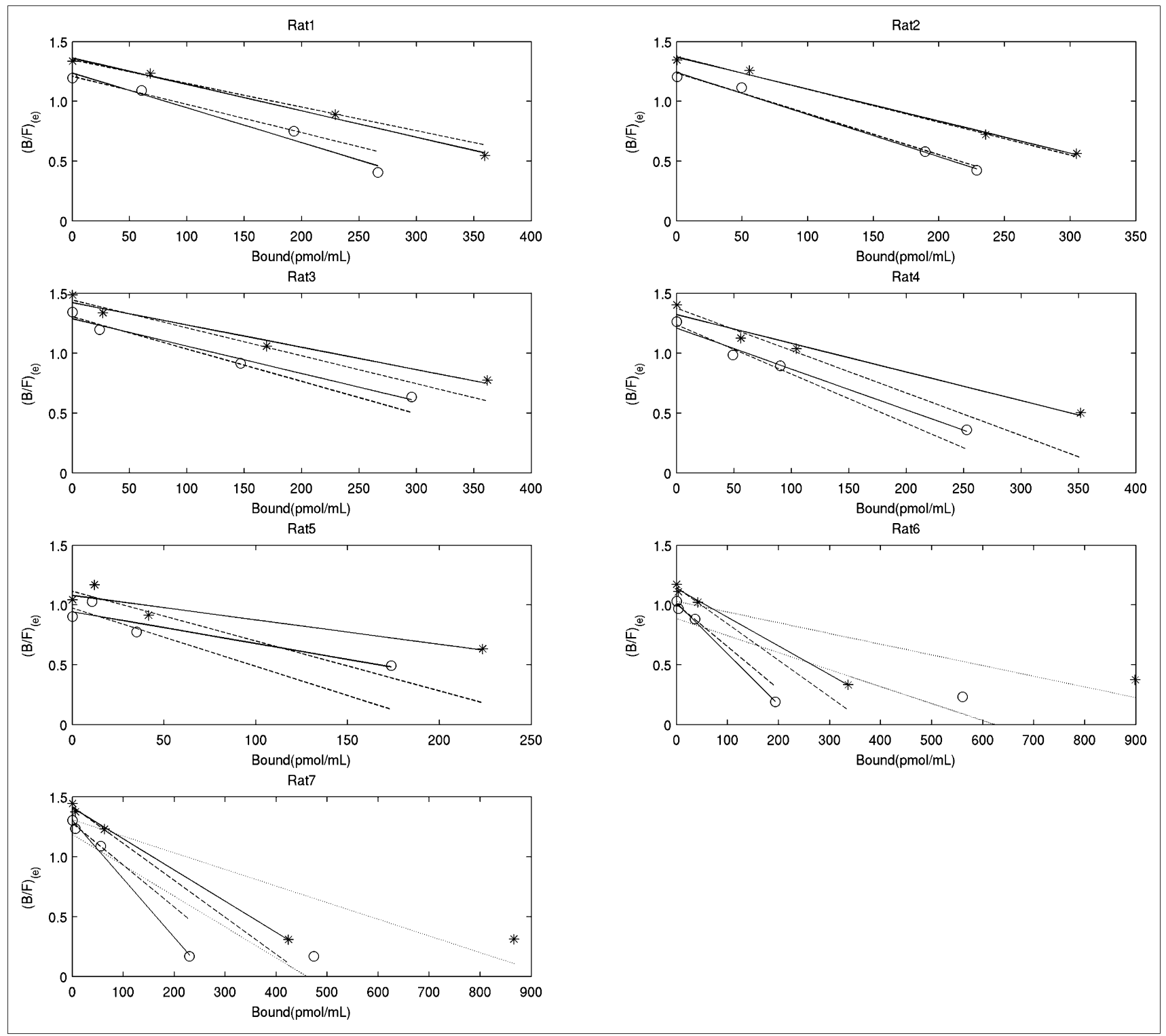

FIGURE 2. Scatchard plots for control side obtained with Equation 4 without NS term $\left({ }^{\star}\right)$, and Equation 5 with NS term subtracted $(\bigcirc)$. Solid lines were obtained with 4-point fit, dashed lines with 3-point fit, and dotted lines with 5-point fit (2 rats only).

estimated for each animal separately were found to agree well with their group-derived values.

\section{Determination of $B_{\max }$ and $K_{d}^{\text {app }}$ Using MLCTA: Lesioned Side}

Results for the lesioned side are shown in Figure 3 and detailed in Supplemental Table 1. The fits to the data became increasingly less reliable with higher denervation severity; for example, for rats 4 and 5 a reliable estimate for $K_{d}^{\text {app }}$ could not be obtained with any method, in contrast to the data from the control side, for which the fitting method did not influence the results. The highest number of plausible fits was obtained when tracer amounts were limited to less than $2.5 \mu \mathrm{g} / 100 \mathrm{~g}$, that is, when only 3 points were included in the fit and NS was subtracted (Eq. 5). In several cases, $(\mathrm{B} / \mathrm{F})_{\mathrm{e}}$ did not appear to change as a function of SA, indicating apparent lack of displacement (Fig. 3).

\section{DD Severity Estimate}

Figure 4 shows the DD estimated according to Equations 6 and 7. The DD estimate without subtraction of the NS term exhibits a clear dependence on tracer SA, especially at higher DD levels. Such dependence decreases with subtraction of the NS term. This finding is consistent with a difference in nondisplaceable binding between the striatum and reference region, which becomes increasingly more relevant for low $(\mathrm{B} / \mathrm{F})_{\mathrm{e}}$ values (low amount of specific binding).

An excellent correlation between DD evaluated from the $(\mathrm{B} / \mathrm{F})_{\mathrm{e}}$ with NS subtracted (Eq. 7) (range [36\%-94\%]) and using the $\mathrm{B}_{\max }$ values as estimated from the linear 3-point 


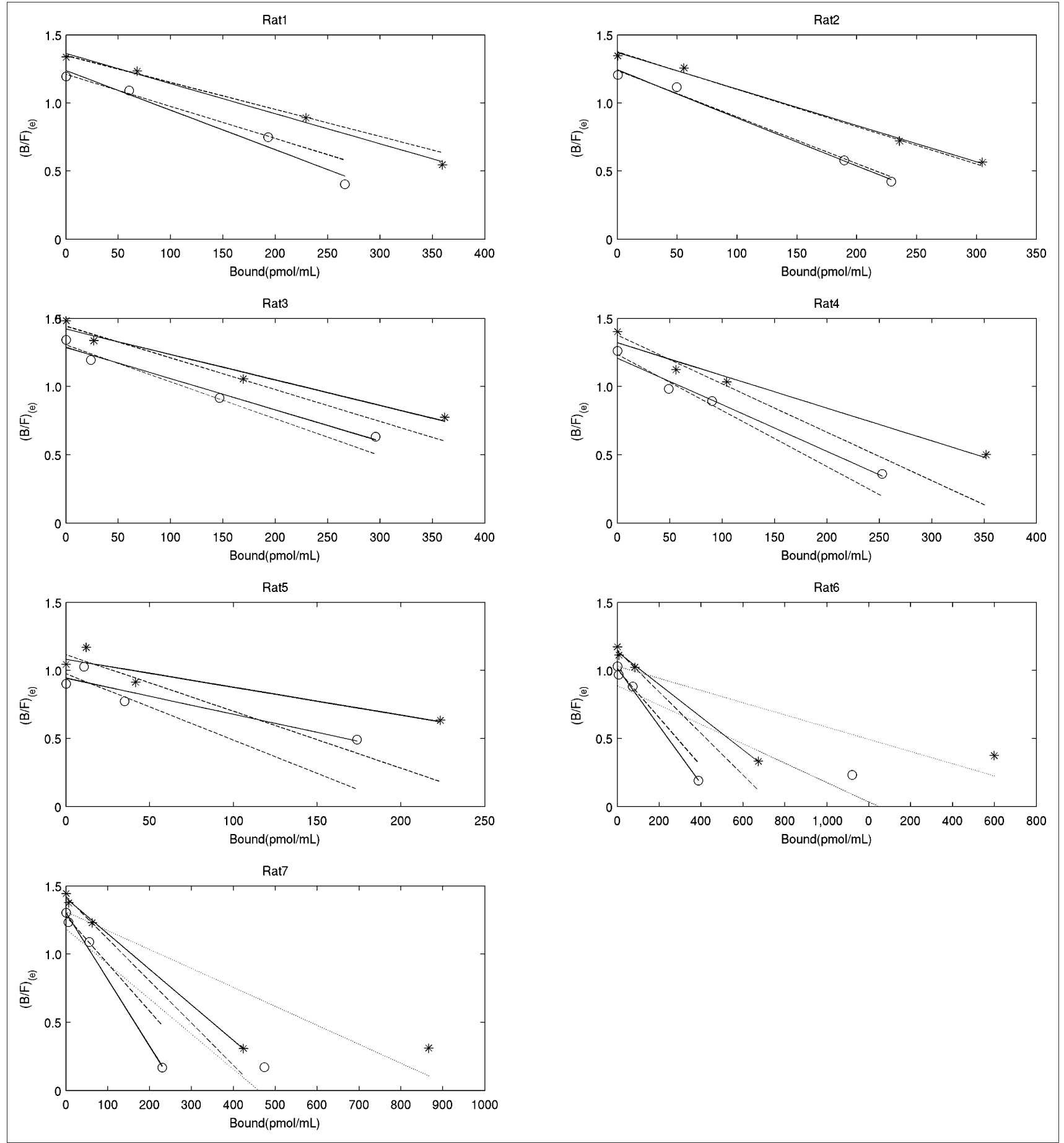

FIGURE 3. Scatchard plots for lesioned side obtained with Equation 4 without NS term (*), and Equation 5 with NS term subtracted ( $\bigcirc)$. Solid lines were obtained with 4-point fit, dashed lines with 3-point fit, and dotted lines with 5-point fit (2 rats only).

Scatchard fits (Eqs. 5 and 8) was found, as shown in Figure 5 , indicating that reasonable values were obtained for $B_{\max }$ even for the lesioned side when the NS term was subtracted and the range of $\mathrm{F}$ limited.

\section{Effect of Lesioning on $B_{\max }$ and $K_{d}^{\text {app }}$}

Data from the 3-point Scatchard were used for this comparison with the NS term subtracted. Rats 4 and 5 were excluded because of unrealistic values obtained in the fit (Supplemental Table 1). Although there was a highly significant difference between the control and lesioned sides for $\mathrm{B}_{\max }$ (control, $402 \pm 94 \mathrm{pmol} / \mathrm{mL}$; lesioned, $117 \pm 120 \mathrm{pmol} / \mathrm{mL} ; P=0.003), \mathrm{K}_{\mathrm{d}}^{\text {app }} \operatorname{did}$ not change as a function of 6-hydroxydopamine lesion (control, $331 \pm 63 \mathrm{pmol} / \mathrm{mL}$; lesioned, $362 \pm 119 \mathrm{pmol} / \mathrm{mL}$; $P=0.63)$. 


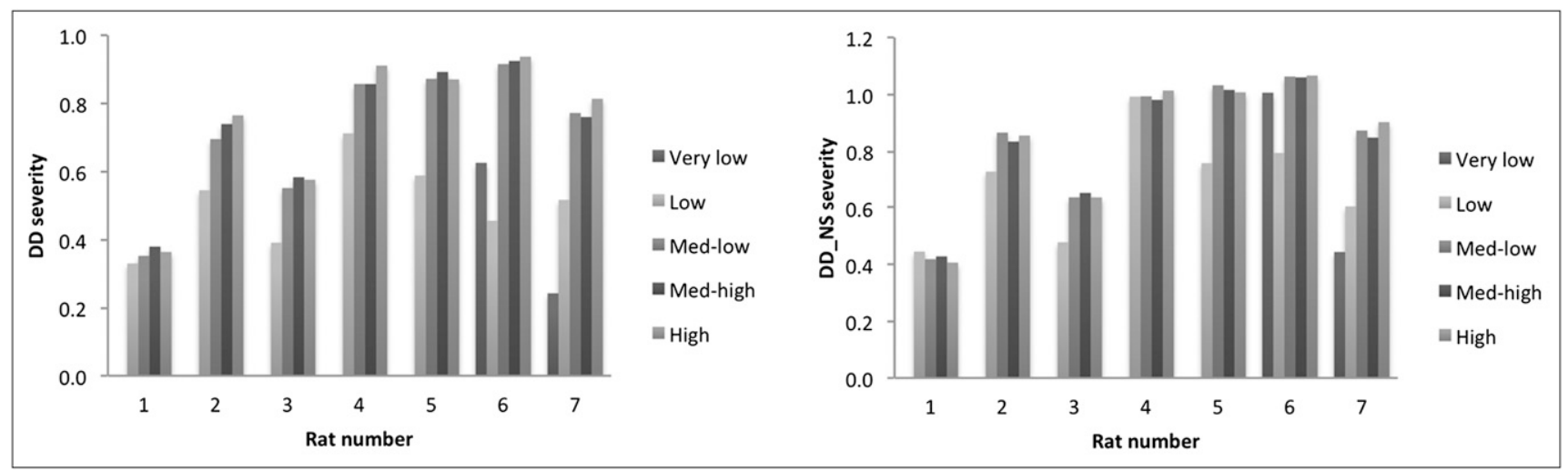

FIGURE 4. Estimate of denervation severity as function of SA for 7 animals without inclusion of NS term (left) (Eq. 6) and with NS term subtracted (right) (Eq. 7).

\section{Occupancy}

Occupancy curves without and with the NS term subtracted are shown in Figure 6. The curves are similar, with a higher occupancy being estimated when the NS term is subtracted. Amounts of tracers and SA required to reach $1 \%$ and $10 \%$ transporter occupancy are detailed in Table 3.

\section{DISCUSSION}

Several observations can be derived from the results. Of immediate practical relevance is the finding that relatively large ${ }^{11} \mathrm{C}$-methylphenidate amounts are required to induce noticeable transporter occupancy. For example, $10 \%$ occupancy is reached with approximately $1.5 \mu \mathrm{g}$ of ${ }^{11} \mathrm{C}$ methylphenidate $/ 100 \mathrm{~g}$ of body weight, whereas only $0.31 \mu \mathrm{g}$ of the vesicular monoamine transporter 2 tracer ${ }^{11} \mathrm{C}$-dyhydrotetrabenazine/100 g of body weight leads to the same fraction of vesicular monoamine transporter 2 occupancy (26). ${ }^{11} \mathrm{C}$-methylphenidate can thus be produced with less stringent constraints on its SA, or conversely, a higher radioactivity dose can be injected, if a better statistical quality of the data is required.

Of more theoretic importance are the results obtained from comparison of the modeling approaches to the determination of $(\mathrm{B} / \mathrm{F})_{\mathrm{e}}, \mathrm{B}, \mathrm{B}_{\max }$, and $\mathrm{K}_{\mathrm{d}}^{\mathrm{app}}$. Although the Logan and SRTM methods yielded consistent results for (B/ F) $)_{\mathrm{e}}$, the estimate of the bound tracer B exhibited a clear dependence on the method used to calculate it. When B was estimated directly from subtraction of the time-activity curve values in the striatum and cerebellum averaged over the last 30 min of data acquisition, both $\mathrm{B}_{\max }$ and $\mathrm{K}_{\mathrm{d}}^{\text {app }}$ were larger than when B was estimated from the SRTM (or Logan) method-derived estimate of $(\mathrm{B} / \mathrm{F})_{\mathrm{e}}$ and $\mathrm{F}$ from the cerebellar time-activity curve. This finding likely reflects a residual time dependence of the bound $B$ and free $F$ tracer concentration as a consequence of the bolus injection method-in contrast to the equilibrium assumption of the MLCTA method-and a difference in the nonspecifically bound tracer concentration between the 2 regions. Taken together, these observations suggest that $\mathrm{B}$ estimated from $(\mathrm{B} / \mathrm{F})_{\mathrm{e}}$ likely provides a more accurate (although not per- fect) estimate of the bound tracer concentration; $(\mathrm{B} / \mathrm{F})_{\mathrm{e}}$ evaluated with the modeling approaches used is not affected by the tracer administration method, and the impact of a different concentration of the nonspecifically bound tracer between the 2 regions is minimized. The bolusplus-constant-infusion method might provide a more accurate estimate of the equilibrium value of $\mathrm{F}$; however, bolus-plus-constant-infusion methods of tracer administration tend to be methodologically more complex and susceptible to a regional variability of the optimal ratio between the amount of tracer administered as a bolus and that administered as a constant infusion.

Possibly the most important outcome of the study is strong evidence of a difference between the nonspecifically bound tracer concentration in the striatum and reference region. An attempt was made to fit the Scatchard plots with a 2-binding-site model, but no meaningful results were obtained, indicating that if a second type of binding site exists, the affinity must be so low that it cannot be reliably

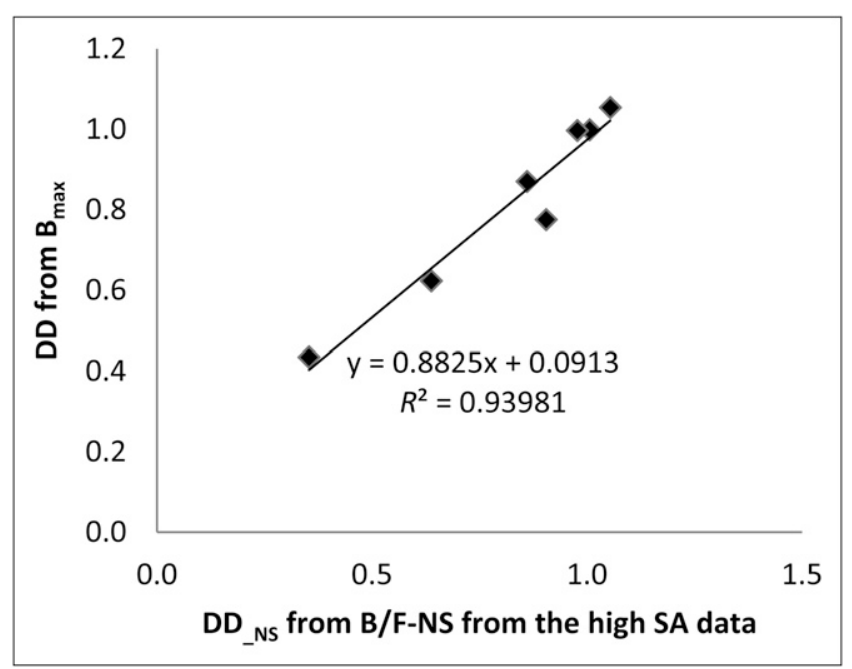

FIGURE 5. Relationship between DD estimated from SRTM derived (B/F) $)_{e}$ with NS subtracted (Eq. 7) and $B_{\max }$ as estimated with Equations 5 and 8. 
FIGURE 6. Occupancy curves without (A) and with (B) NS term subtracted as function of tracer amount. Asterisks show 1\% and $10 \%$ occupancy values. Similar plots are obtained when occupancy is plotted as function of $\log (1 / S A)$.
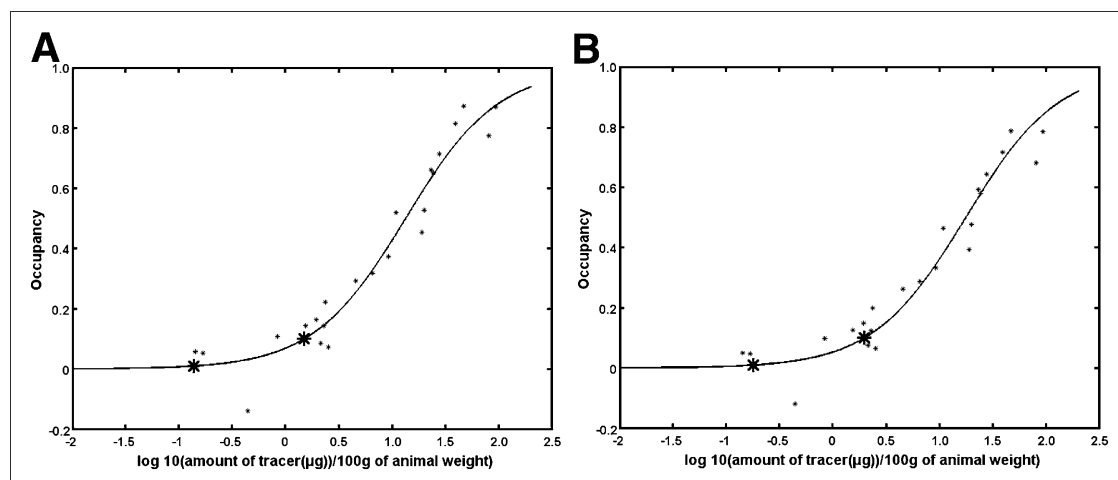

measured with the present data. Of course, it is possible that the high doses of ${ }^{11} \mathrm{C}$-methylphenidate, administered when the ligand was produced at very low SA, might introduce secondary pharmacologic effects, which could confound the MLCTA and occupancy analyses (27). Interestingly, in both rat and mouse groups, derived $\mathrm{B}_{\max }$ and $\mathrm{K}_{\mathrm{d}}^{\text {app }}$ values for ${ }^{11} \mathrm{C}$-raclopride ( $\mathrm{a}_{2}$-type receptor antagonist) are better defined using an expression explicitly accounting for an NS term $(19,28)$.

To test this hypothesis, we revisited the comparison between DD severity measured in vivo by ${ }^{11} \mathrm{C}$-methylphenidate PET and by in vitro ${ }^{3} \mathrm{H}$-WIN 35,428 autoradiography performed on extracted brain slices of the same animals. The original comparison was performed on a group of 16 rats and was part of a previously published study (22) in which all the scans were obtained with ${ }^{11} \mathrm{C}$-methylphenidate produced at an SA high enough to ensure negligible transporter occupancy $(>40.7 \mathrm{kBq} / \mathrm{pmol})$. PET-derived DD for those data was now estimated without and with subtraction of the NS term, with value fixed at the currently estimated 0.14 . When the NS term is subtracted from the $\mathrm{BP}_{\mathrm{ND}}$, the correlation between the PET- and autoradiography-derived DD values virtually follows the line of identity, whereas the PET-derived DD values underestimate the autoradiography-derived DD values without subtraction of the NS term (Fig. 7). This finding argues against the supposition that the NS term might arise as a consequence of a methodologic confound due to a pharmacologic effect of larger amounts of ${ }^{11} \mathrm{C}$-methylpheni- date and suggests that it is indeed a characteristic of ${ }^{11} \mathrm{C}$-methylphenidate binding. The origin and exact interpretation of such a term is at present speculative, and further comparisons to ex vivo or in vitro data must be performed to correctly identify its meaning. Further studies at very low SA are also required to precisely determine its value.

Despite these limitations, and the admitted uncertainty about the exact interpretation and value of the NS term, we deemed that a more informative comparison between the estimated $\mathrm{B}_{\max }$ and $\mathrm{K}_{\mathrm{d}}^{\mathrm{app}}$ of the control and 6-hydroxydopamine-lesioned side is obtained when the NS term is explicitly considered. Although a significant difference was found for $B_{\max }$ between the lesioned and control sides, no such difference was observed for $K_{d}^{\text {app }}$, indicating that the decreased value of $\mathrm{BP}_{\mathrm{ND}}$ as estimated from the high $\mathrm{SA}(\mathrm{B} / \mathrm{F})_{\mathrm{e}}$ on the lesion side indicates a reduction in transporter density, rather than being reflective of competitive endogenous ligand changes. The finding that chronic degeneration of the nigral dopamine terminals affects primarily $B_{\max }$ is consistent with studies using other pre- and postsynaptic ligands in both human and nonhuman primates with raclopride $(29,30)$ or in rodents with ${ }^{11} \mathrm{C}$-dyhydrotetrabenazine (26). This might in turn suggest that changes in $\mathrm{K}_{\mathrm{d}}^{\text {app }}$ may occur mostly as a mechanism to adapt rapidly to acute changes in the receptor or transporter environment.

Finally, it is of interest to compare the behavior of ${ }^{11} \mathrm{C}$ methylphenidate DAT binding with that of other tracers used to investigate the dopaminergic system in rats. Similar

TABLE 3

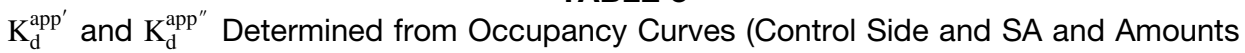
Leading to $1 \%$ and $10 \%$ Occupancy)

\begin{tabular}{|c|c|c|c|}
\hline NS & Parameter & $1 \%$ occupancy & $10 \%$ occupancy \\
\hline & $\mathrm{K}_{\mathrm{d}}^{\mathrm{app}}(\mathrm{pmol} / \mathrm{kBq})$ & SA & SA \\
\hline $\mathrm{N}$ & 20.7 & 4.3 & 0.43 \\
\hline $\mathrm{Y}$ & 15.7 & 5.7 & 0.57 \\
\hline & $\mathrm{K}_{\mathrm{d}}^{\mathrm{app}}$ ( $\mu \mathrm{g}$ of tracer/100 $\mathrm{g}$ of animal weight) & Amount & Amount \\
\hline $\mathrm{N}$ & 17.7 & 0.18 & 2.0 \\
\hline $\mathrm{Y}$ & 13.3 & 0.14 & 1.5 \\
\hline
\end{tabular}




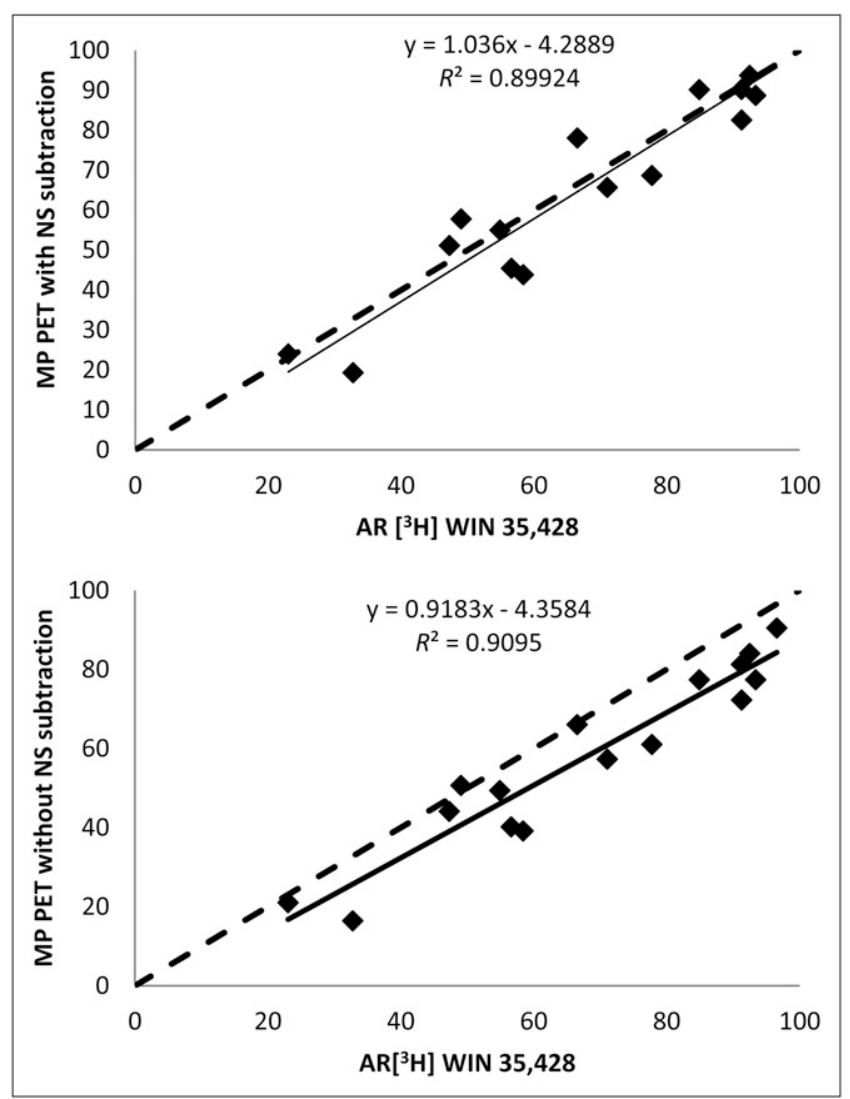

FIGURE 7. Comparison of DD severity estimate between ${ }^{11} \mathrm{C}$ methylphenidate PET and ${ }^{3} \mathrm{H}-$ WIN 35,428 autoradiography. Solid line $=$ line of best fit; dashed line $=$ line of identity.

occupancy studies performed with ${ }^{11} \mathrm{C}$-dyhydrotetrabenazine on unilaterally 6-hydroxydopamine-lesioned rats demonstrated very different characteristics: no dependence of DD severity estimate on tracer SA and excellent linearity of the Scatchard plots over a wide range of free (or bound) tracer concentrations, thus presenting no evidence of a difference in the concentration of the nonspecifically bound tracer between the striatum and reference region (26). Because the impact of the NS term is particularly relevant to a situation of high denervation severity, care must be taken when comparing outcomes of multitracer studies in such a situation.

The impact of these findings on human DAT imaging with ${ }^{11} \mathrm{C}$-methylphenidate cannot be readily assessed with these results. Interspecies differences and the nature of the neurotoxin 6-hydroxydopamine-induced lesion could invalidate a direct extrapolation of these results to the human case. Nevertheless, these data might suggest the need for caution in interpreting ${ }^{11} \mathrm{C}$-methylphenidate DAT binding in extreme disease situations.

\section{CONCLUSION}

We have investigated the characteristics and limitations of ${ }^{11} \mathrm{C}$-methylphenidate-derived DAT imaging with PET in a unilateral 6-hydroxydopamine rat model of Parkinson disease. This study established useful limits to the amount of administered tracer to avoid confounding tracer mass effects and demonstrated the feasibility of determining $\mathrm{B}_{\max }$ and $\mathrm{K}_{\mathrm{d}}^{\text {app }}$ separately for ${ }^{11} \mathrm{C}$-methylphenidate-DAT binding in rats. $\mathrm{B}_{\max }$ and $\mathrm{K}_{\mathrm{d}}^{\mathrm{app}}$ analysis performed with the control striatum data obtained from scans of rats injected with ${ }^{11} \mathrm{C}$-methylphenidate produced at different specific activities strongly suggested a difference in nonspecific binding between the striatum and reference region. The estimates of $B_{\max }$ and $K_{d}^{\text {app }}$ were found to be dependent on the method of analysis used, especially for the lesioned side, but were more consistent when the difference in nonspecific binding was explicitly accounted for. Although the origin and exact interpretation of what appears to be additional nonspecific ${ }^{11} \mathrm{C}$-methylphenidate binding in the striatum, compared with the cerebellum, was not identified, these data indicate that caution is required in comparing binding of different dopaminergic tracers in a situation of high DD severity.

\section{DISCLOSURE STATEMENT}

The costs of publication of this article were defrayed in part by the payment of page charges. Therefore, and solely to indicate this fact, this article is hereby marked "advertisement" in accordance with 18 USC section 1734.

\section{ACKNOWLEDGMENTS}

We thank Siobhan McCormick and Rick Kornelsen for imaging and animal handling. This work was supported by grants from the Natural Science and Engineering Research Council and the Michael Smith Foundation for Health Research. No other potential conflict of interest relevant to this article was reported.

\section{REFERENCES}

1. de Lau LM, Breteler MM. Epidemiology of Parkinson's disease. Lancet Neurol. 2006;5:525-535.

2. Gainetdinov RR, Fumagalli F, Jones SR, Caron MG. Dopamine transporter is required for in vivo MPTP neurotoxicity: evidence from mice lacking the transporter. J Neurochem. 1997;69:1322-1325.

3. Bannon MJ. The dopamine transporter: role in neurotoxicity and human disease. Toxicol Appl Pharmacol. 2005;204:355-360.

4. Nandhagopal R, Mak E, Schulzer M, et al. Progression of dopaminergic dysfunction in a LRRK2 kindred: a multitracer PET study. Neurology. 2008;71: 1790-1795.

5. Sossi V, la Fuente-Fernández R, Nandhagopal R, et al. Dopamine turnover increases in asymptomatic LRRK2 mutations carriers. Mov Disord. 2010;25:2717-2723.

6. Lee CS, Samii A, Sossi V, et al. In vivo positron emission tomographic evidence for compensatory changes in presynaptic dopaminergic nerve terminals in Parkinson's disease. Ann Neurol. 2000;47:493-503.

7. Sossi V, de la Fuente-Fernández R, Schulzer M, Troiano AR, Ruth TJ, Stoessl AJ. Dopamine transporter relation to dopamine turnover in Parkinson's disease: a positron emission tomography study. Ann Neurol. 2007;62:468-474.

8. Troiano AR, de la Fuente-Fernandez R, Sossi V, et al. PET demonstrates reduced dopamine transporter expression in PD with dyskinesias. Neurology. 2009;72: 1211-1216.

9. Cilia R, Ko JH, Cho SS, et al. Reduced dopamine transporter density in the ventral striatum of patients with Parkinson's disease and pathological gambling. Neurobiol Dis. 2010;39:98-104.

10. Sossi V, Dinelle K, Schulzer M, Mak E, Doudet DJ, de la Fuente-Fernández R. Levodopa and pramipexole effects on presynaptic dopamine PET markers and estimated dopamine release. Eur J Nucl Med Mol Imaging. 2010;37:2364-2370. 
11. Parkinson's Study Group. Dopamine transporter brain imaging to assess the effects of pramipexole vs levodopa on Parkinson's disease progression. JAMA. 2002;287:1653-1661.

12. Guttman M, Stewart D, Hussey D, Wilson A, Houle S, Kish S. Influence of L-dopa and pramipexole on striatal dopamine transporter in early PD. Neurology. 2001;56:1559-1564.

13. Blandini F, Armentero MT, Martignoni E. The 6-hydroxydopamine model: news from the past. Parkinsonism Relat Disord. 2008;14(suppl 2):S124-S129.

14. Cenci MA, Ohlin KE. Rodent models of treatment-induced motor complications in Parkinson's disease. Parkinsonism Relat Disord. 2009;(suppl 4):S13-S17.

15. Innis RB, Cunningham VJ, Delforge J, et al. Consensus nomenclature for in vivo imaging of reversibly binding radioligands. J Cereb Blood Flow Metab. 2007; 27:1533-1539.

16. Logan J, Fowler JS, Volkow ND, Wang GJ, Ding YS, Alexoff DL. Distribution volume ratios without blood sampling from graphical analysis of PET data. J Cereb Blood Flow Metab. 1996;16:834-840.

17. Lammertsma AA, Hume SP. Simplified reference tissue model for PET receptor studies. Neuroimage. 1996;4:153-158.

18. Topping GJ, Dinelle K, Kornelsen R, McCormick S, Holden JE, Sossi V. Positron emission tomography kinetic modeling algorithms for small animal dopaminergic system imaging. Synapse. 2010;64:200-208.

19. Schiffer WK, Alexoff DL, Shea C, Logan J, Dewey SL. Development of a simultaneous PET/microdialysis method to identify the optimal dose of ${ }^{11} \mathrm{C}$-raclopride for small animal imaging. J Neurosci Methods. 2005;144:25-34.

20. Holden JE, Jivan S, Ruth TJ, Doudet DJ. In vivo receptor assay with multiple ligand concentrations: an equilibrium approach. J Cereb Blood Flow Metab. 2002;22:1132-1141.
21. Studenov AR, Jivan S, Lu J, et al. J Labelled Comp Radiopharm. 1994;49: $455-458$.

22. Sossi V, Dinelle K, Topping G, et al. Dopamine transporter relation to levodopaderived synaptic dopamine in a rat model of Parkinsonism's: an in vivo imaging study. J Neurochem. 2009;109:85-92.

23. Breese GR, Traylor TD. Depletion of brain noradrenaline and dopamine by 6-hydroxydopamine. Br J Pharmacol. 1971;42:88-99.

24. Kim JS, Lee JS, Im KC, et al. Performance measurement of the microPET Focus 120 scanner. J Nucl Med. 2007;48:1527-1535.

25. Rubins DJ, Meadors AK, Yee S, Melega WP, Cherry SR. Evaluation of a stereotactic frame for repositioning of the rat brain in serial positron emission tomography imaging studies. J Neurosci Methods. 2001;107:63-70.

26. Sossi V, Holden JE, Topping GJ, et al. In vivo measurement of density and affinity of the monoamine vesicular transporter in a unilateral 6-hydroxydopamine rat model of PD. J Cereb Blood Flow Metab. 2007;27:1407-1415.

27. Doudet DJ, Holden JE. Sequential versus nonsequential measurement of density and affinity of dopamine D2 receptors with $\left[{ }^{11} \mathrm{C}\right]$ raclopride: effect of methamphetamine. J Cereb Blood Flow Metab. 2003;23:1489-1494.

28. Fischer K, Sossi V, Schmid A, et al. Noninvasive nuclear imaging enables the in vivo quantification of striatal dopamine receptor expression and raclopride affinity in mice. J Nucl Med. 2011;52:1133-1141.

29. Rinne JO, Laihinen A, Ruottinen H, et al. Increased density of dopamine D2 receptors in the putamen, but not in the caudate nucleus in early Parkinson's disease: a PET study with $\left[{ }^{11} \mathrm{C}\right]$ raclopride. J Neurol Sci. 1995;132:156-161.

30. Doudet DJ, Jivan S, Ruth TJ, Holden JE. Increased density of dopamine D2 receptors in the putamen, but not in the caudate nucleus in early Parkinson's disease: a PET study with $\left[{ }^{11} \mathrm{C}\right]$ raclopride. Synapse. 2002;44:198-202. 